\title{
Influence of particle shape and sorting upon sample size estimates for a coarse-grained upland stream
}

\author{
David J. Milan $^{\mathrm{a}, *}$, George L. Heritage ${ }^{\mathrm{b}}$, Andrew R.G. Large ${ }^{\mathrm{a}}$, Christopher F. Brunsdon ${ }^{\mathrm{a}}$ \\ ${ }^{a}$ Department of Geography, University of Newcastle upon Tyne, Newcastle upon Tyne NE1 7RU, UK \\ ${ }^{b}$ Department of Geography, University of Salford, Salford M5 4WP, UK
}

Received 2 March 1998; accepted 22 July 1999

\begin{abstract}
Present bulk-sampling recommendations for the characterisation of fluvial sediments based upon ellipsoids of revolution do not take into account variations in particle shape and sorting. Disc-shaped particles with equivalent $b$-axes to spheres have lower relative masses and require more relaxed sampling criteria compared to existing recommendations, whereas heavier cube- and rod-shaped particles require more stringent criteria. Empirical data from the River Rede, Northumberland, UK, an upland gravel-bed channel, indicate that samples are dominated by discs. However, particle shape was not constant in every grain-size fraction; blocky material (cubes and rods) was more frequent in the $>63 \mathrm{~mm}$ fraction in comparison to the other finer fractions. Data based on the weight of the $D_{99.9}$ particle indicate that a larger sample weight is required when the coarsest size category of that sample is dominated by blocky material. Sorting also affects the size of the sample required to characterise a deposit; the more poorly sorted the deposit, the larger the sample has to be or the finer should be the truncation grain size. This is particularly evident in samples with a high matrix concentration. Two sample reference lines, developed from these data using the $0.1 \%$ by mass criteria, recommend larger minimum sample sizes (or finer truncation) in comparison to other published standards. Data from a second site support these results, indicating that they may be applicable to other poorly sorted upland gravel-bed streams. Analysis of the size category variance demonstrates that the new guidelines returned the lowest variance levels, suggesting that they should be used where particularly accurate sampling procedures are required. (c) 1999 Elsevier Science B.V. All rights reserved.
\end{abstract}

Keywords: sediments; sample size; shape; sorting; truncation; fluvial gravel; freeze-cores

\section{Introduction}

This paper discusses an important refinement of sampling criteria for characterising the texture of fluvial gravels. The topic is of significant interest not only to sedimentologists, but also to fisheries ecologists as it leads to substrate sampling criteria for determining fish habitat quality. Texture

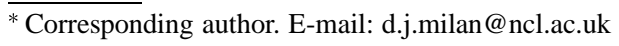

characterisation is problematic in that large sample volumes are required to accurately describe coarse fluvial sediment. Indeed, the impracticality of obtaining such samples has long been recognised (for example Wentworth, 1926; Krumbein and Pettijohn, 1938), and remains a fundamental difficulty (Klingeman and Emmett, 1982; Gomez, 1983; Mosely and Tindale, 1985; Church et al., 1987; Rice and Church, 1996; Ferguson and Paola, 1997). Some workers (for example Wentworth, 1926, and Wolman, 1954) have 
presented ‘ideal minimum' and 'suggested practical' sample sizes for gravel deposits. Based upon these and other observations, several organisations have recommended standards indicating the size of the bulk sample required to obtain representative results (for example the British Standards Institute, 1985, and the American Society for Testing and Materials, 1987). The majority of these are based on bulk sampling, and only the methods of de Vries (1970) and Church et al. (1987) have been based on a consideration of individual size fractions. de Vries' recommendations incorporate individual fractions of fluvial sand and fine gravel and determine a minimum sample size based on the $D_{84}$ of the bed-material, the value defined by de Vries as the reference 'large' grain-size from which an estimate sample is obtained.

\subsection{Recent approaches}

The recommendations of Church et al. (1987, hereinafter referred throughout simply as 'Church et al.') were similar to those of de Vries, and were based on the premise that the largest grains present in the sample should determine the sample size. This is due to the fact that they are fewest in quantity, and hence the least well-represented. Church et al. assumed particles to be ellipsoids of revolution, with clast weights equalling:

$\rho_{\mathrm{s}}\left(\pi \frac{D_{\mathrm{g}}^{3}}{6}\right)$

where $D_{\mathrm{g}}$ is the geometric mean radius of the fraction, and $\rho_{\mathrm{s}}$ is the mineral density of the sediment $\left(2.65 \mathrm{~g} \mathrm{~cm}^{-3}\right)$. This formula gives an approximation of the weight, which assumes that $D_{\mathrm{g}}^{3}$ adequately represents the $a$-, $b$ - and $c$-axes. Church et al. concluded that a minimum of 100 particles are required in each $0.5 \phi$-fraction if a statistically stable measure of the proportion of the entire sample in that fraction is to be obtained (grain shape was assumed to remain constant throughout the grain-size distribution). From their analysis, it was determined that the largest grain in the coarsest stable size fraction should constitute at most $0.1 \%$ of the total sample mass, a figure proposed as a suitable criterion upon which to determine minimum sample size. However,

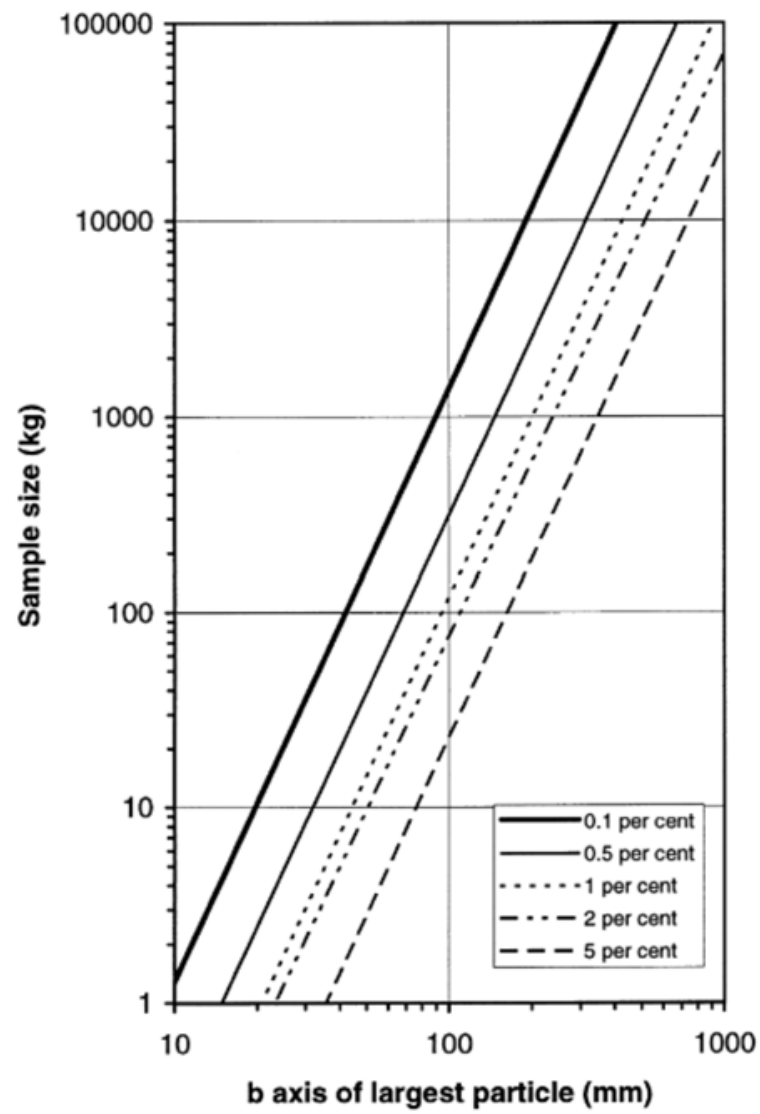

Fig. 1. Bulk sample standards developed by Church et al. (1987) (0.1\%, $0.5 \%$ and $1 \%$, and Mosely and Tindale (1985) (5\%). The percentage attributed to each line represents the percent by weight of the sample that is contributed by the largest stone.

for studies involving material coarser than $64 \mathrm{~mm}$, sample sizes become impracticably large for hand operation and require specialist machinery for their successful recovery. As a result, Church et al. recommend using the $0.1 \%$ value up to $32 \mathrm{~mm}$, and 1\% between 32 to $128 \mathrm{~mm}$ (Fig. 1). As a comparison, empirically based work of Mosely and Tindale (1985) recommends that the largest particle should not constitute more than $5 \%$ of the sample.

\subsection{Truncation}

Where it is clear that sample size is inadequate to accurately represent the whole population, meaningful information can be still obtained if the grain-size distribution is truncated at the largest size which is 
known to have been sampled representatively (Rood and Church, 1994). This may be estimated by entering sample weight into Fig. 1 and by reading off the intercept grain size for the desired level of accuracy. For a sample to be truly representative of a population, each particle size must appear in its true proportions. With bulk sampling of sub-surface material in gravel-bed river channels coarse particles tend to be under-represented, as it is not possible nor feasible to sample the entire river bed. The bulk sample obtained is representative only to a critical grain-size below which all grains appear in their true proportions, and beyond which coarser grains do not. Interpretation should thus be restricted to the proportion of the particle-size distribution which has been sampled representatively, and it is therefore necessary to truncate bulk samples that are not representative of the entire population in order to comply with this requirement. Under-represented sizes should be discarded, and the size distribution recalculated on the basis of the sub-truncation sizes only.

\subsection{The influence of particle shape}

This paper investigates the degree to which particle shape and sorting bias current sampling recommendations, and tackles the issue of sample truncation. Church et al.'s original work was based upon intrusive, metamorphic and volcanic rocks in which there did not appear to be any strong anisotropy in primary joint patterns (M. Church, pers. commun., 1998). The rocks were all fairly equant in at least two dimensions, which explains the apparent success of using the spheroid of revolution approximation to address particle shape. One drawback is that present guidelines available in the literature do not take into account the variation in particle shape which occurs in nature. Yet, using exact formulae for different shapes should yield a larger particle weight for relatively blocky (cubes and rods) clasts, and a smaller weight for relatively asymmetrical ones (discs) of the same nominal diameter (Table 1). Therefore, using the approach outlined by Church et al. (1987) but considering different shape criteria, a larger sample (or finer truncation) size would be required for blocky material and a smaller sample (or coarser truncation) size for disc-dominated samples.
Table 1

Formulae used to calculate volume of different shaped clasts (after Beyer, 1991), where $a, b$ and $c$ are the primary, secondary and tertiary clast semi-axes respectively

\begin{tabular}{ll}
\hline Shape & Volume \\
\hline Disc: (oblate spheroid) & $\frac{4}{3} \pi a^{2} c$ \\
Rod: (prolate spheroid) & $\frac{4}{3} \pi a c^{2}$ \\
Blade: (triaxial) & $\frac{4}{3} \pi a b c$ \\
Sphere & $\frac{4}{3} \pi a^{3}$ \\
Cube $^{\text {a }}$ & $a b c$ \\
\hline
\end{tabular}

a The volume of a cube is calculated using the full length of each axis.

\section{Study sites}

The study focused on two 120-m reaches on the River Rede, Northumberland, UK, an upland gravel-bed stream. The Rede has a Strahler order of four, and has its source area in the Cheviot Hills at $490 \mathrm{~m}$ above Ordnance datum. The study reaches were selected on the basis of their well-defined sequences of pools and riffles and were located 4.5 $\mathrm{km}$ and $7.5 \mathrm{~km}$ from the source of the river, having catchment areas of $18 \mathrm{~km}^{2}$ and $41 \mathrm{~km}^{2}$, respectively (Fig. 2). Site A (Grid reference NT 721 043) is unregulated and experiences a flashy hydrological regime, while Site B (NT 753 032) has been regulated since 1905 by the Catcleugh reservoir. The compensation flow is set at $0.158 \mathrm{~m}^{3} \mathrm{~s}^{-1}$; however, occasional floods overtop the spill-weir. The oldest rocks in the Rede catchment are Silurian greywackes and shales. Devonian andesite lavas, part of a major igneous complex of the Cheviot Hills, overlie these Silurian sediments, while Lower Carboniferous Fell sandstones predominate throughout the upper part of the catchment, interspersed with Scemerston coals, and the middle and lower limestone group. This mixed lithology is reflected in the bedload material within the River Rede main channel, and influences grain shape at any given point along the channel. The proximity of the sampling sites to the source area also has a key role to play in shaping clasts. Those close to the source (and possibly more resistant) show jointing features or an increased blocky nature related to the character of the parent rock, while those further away (and less resistant) are typically of a more spherical nature. 


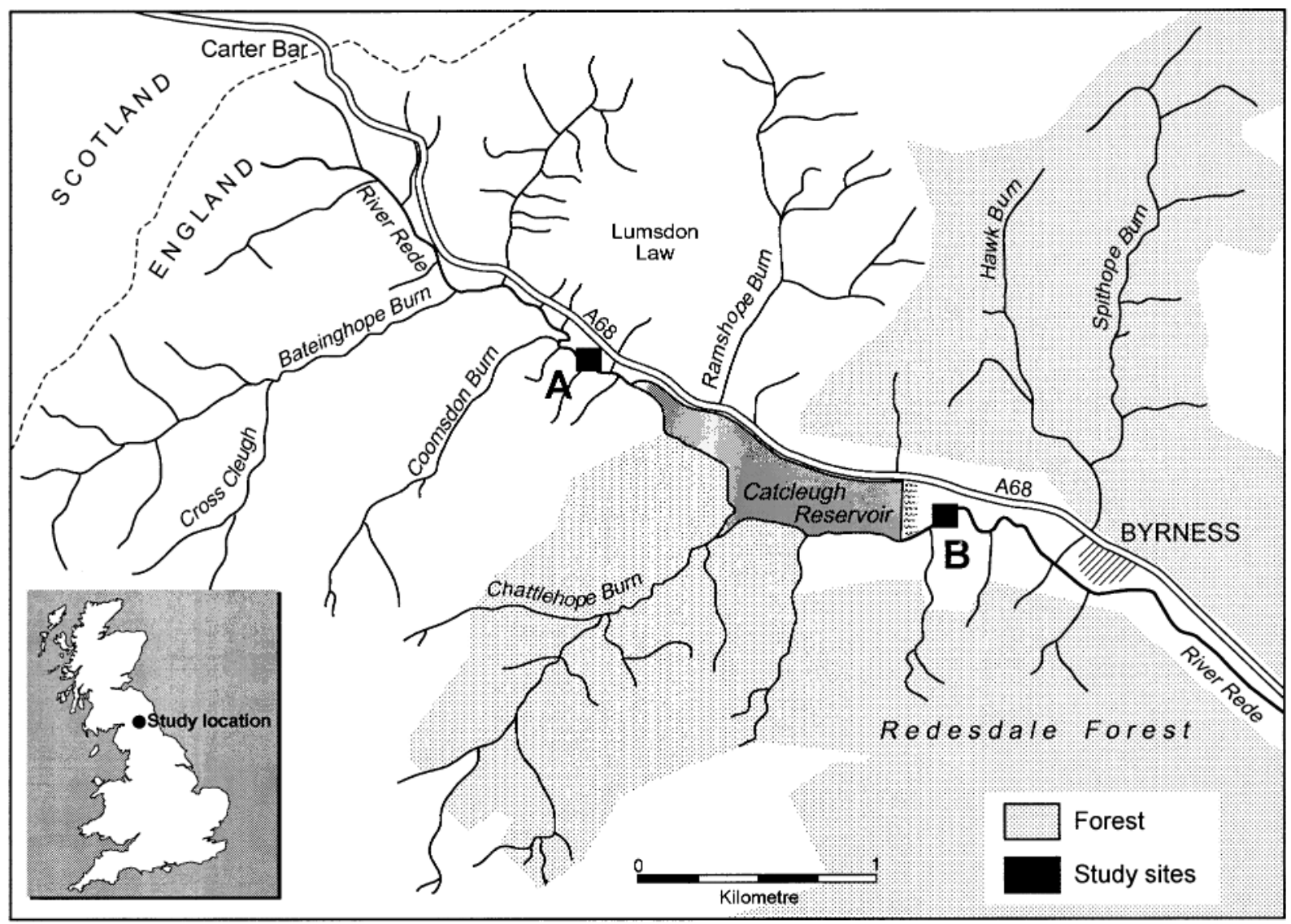

Fig. 2. Study sites $(A$ and $B$ ) above and below Catcleugh reservoir on the River Rede, Northumberland. Light grey shading indicates coniferous forest plantations. Unshaded areas are moorland.

\section{Methods and results}

\subsection{The representative nature of the sampling strategy}

Freeze-coring (Stocker and Williams, 1972; Milan, 1994) was used to sample sub-surface bed sediments up to a maximum depth of $60 \mathrm{~cm}$. The technique allows relatively undisturbed samples of sediment to be obtained, and enables retention of the finegrained matrix fraction commonly lost using other sampling methods (Thoms, 1992). A total of 166 cores (80 from Site A and 86 from Site B) were obtained from sequential riffles at both sites, and were sectioned into $15-\mathrm{cm}$ intervals to provide supporting information on the vertical variation in grain-size distribution. Freeze-cores obtained from Site A averaged
$48 \mathrm{~cm}$ in length (often limited by the depth of available gravel), $26 \mathrm{~cm}$ in width, weighed $17 \mathrm{~kg}$ in their frozen state, and had mean volumes and bulk densities of $7637 \mathrm{~cm}^{3}$ and $2240 \mathrm{~kg} \mathrm{~m}^{-3}$, respectively (Table 2). Wolcott and Church (1991) have demonstrated that, where the spatial variability of sediment properties is of little interest, the overall mean grain-size distribution of a 'site' may be described by combining cores. Knowing the maximum clast size, the number of cores required is provided by the sample weight from Church et al.'s chart (cf. Fig. 1) divided by the mean weight of a single core. In this study, a total dry weight of $1305 \mathrm{~kg}$ was obtained from Site A, sufficient to represent particles of up to $150 \mathrm{~mm}$ (the $D_{99.5}$ of the reach as shown by the 'no truncation' curve in Fig. 3).

Sampling error in relation to sample size could also be estimated using Eq. 2, where the number 
Table 2

Summary of frozen 'wet-state' freeze-core data for three riffles at Site A

\begin{tabular}{lllllll}
\hline Riffle & $N$ & $\begin{array}{l}\text { Average length } \\
(\mathrm{cm})\end{array}$ & $\begin{array}{l}\text { Average width } \\
(\mathrm{cm})\end{array}$ & $\begin{array}{l}\text { Average weight } \\
(\mathrm{kg})\end{array}$ & $\begin{array}{l}\text { Average volume } \\
\left(\mathrm{cm}^{3}\right)\end{array}$ & $\begin{array}{l}\text { Bulk density } \\
\left(\mathrm{kg} \mathrm{m}^{-3}\right)\end{array}$ \\
\hline 1 & 18 & $57.3(50.0-64.0)$ & $24.1(16.0-33.0)$ & $17.28(11.45-26.35)$ & $7840.96(5584.0-12100.0)$ & $2186.17(1907.1-2472.4)$ \\
2 & 18 & $53.6(28.0-60.0)$ & $27.7(20.0-36.0)$ & $19.87(6.93-32.25)$ & $8716.99(677.7-14152.2)$ & $2336.81(2278.8-14719.7)$ \\
3 & 16 & $34.2(15.0-53.0)$ & $25.9(20.0-35.0)$ & $14.81(4.29-26.78)$ & $6191.85(2057.11-13563.5)$ & $2162.52(1974.41-2331.8)$ \\
Mean & & 48.4 & 25.9 & 17.42 & 7636.8 & 2239.8 \\
\hline
\end{tabular}

Figures in brackets indicate minimum and maximum measured values. Volumes were estimated using a water displacement technique.

of freeze-cores $(N)$ required to represent granular variation within the substrate may be determined for a prescribed level of accuracy, $d$ (log units to normalise the distribution), given the standard deviation of the sample $D_{50}, s$, of the initial sample size, $n$, and the $t$ value for $n-1$ degrees of freedom (Hey and Thorne, 1983):

$N=\left(\frac{t s}{d}\right)^{2}$

The plot of error, for $D_{50}$ estimation versus sample size shown in the inset to Fig. 3 demonstrates that the error flattens out and becomes negligible after around 50 cores have been sampled. It is thus reasonable to assume that the grain size distribution based on the bulked sample of 80 cores closely approximates the population grain size distribution of the sample unit for the River Rede.

\subsection{Influence of grain shape}

To determine exactly how different grain shapes alter Church et al.'s recommendations, theoretical $0.1 \%$ lines for perfect cubes, rods, spheres, blades

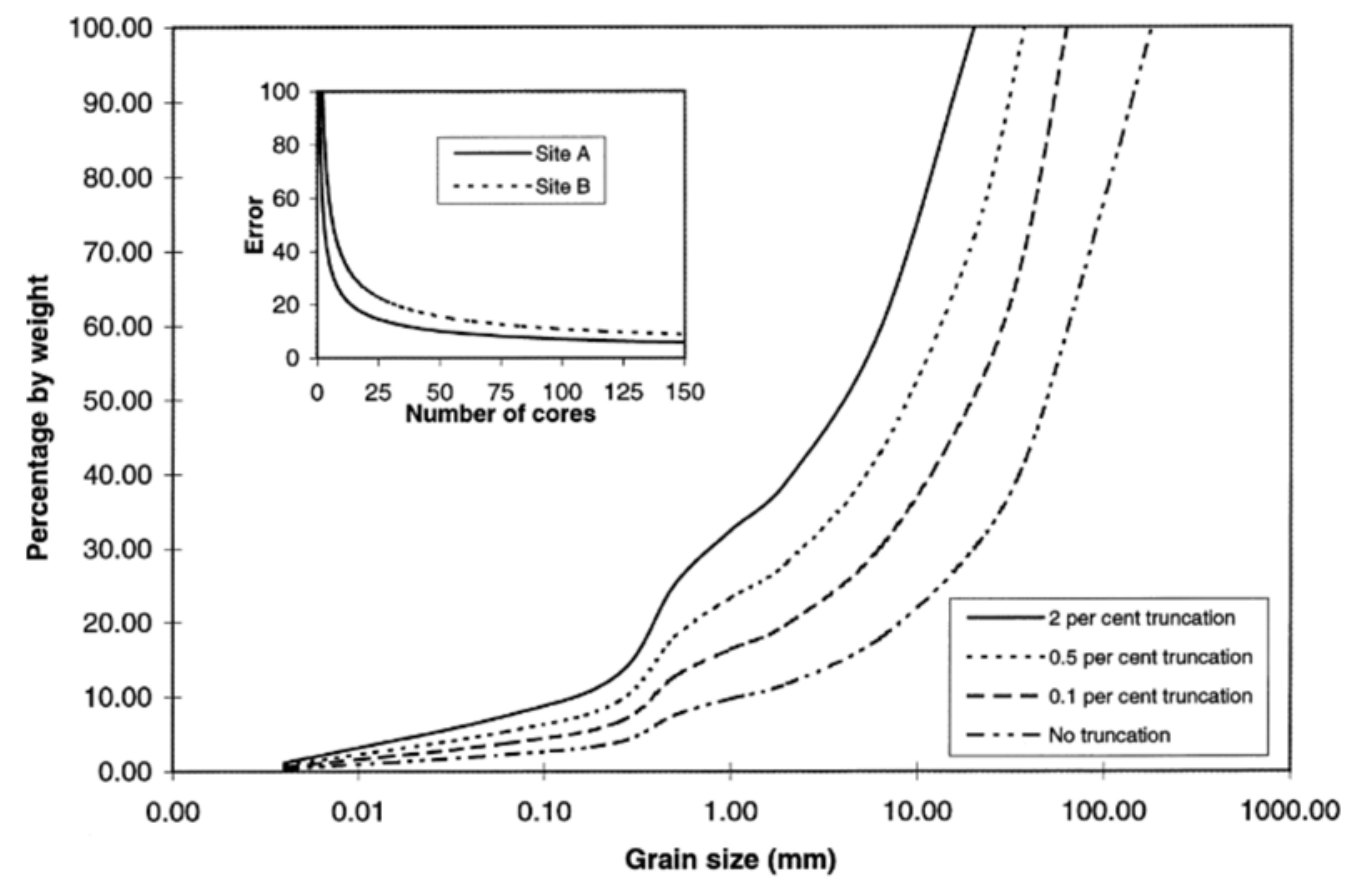

Fig. 3. Effects of $0.1 \%, 0.5 \%$ and $2 \%$ truncation upon the grain-size distribution (each line represents a mean of an 80 core sample). The plot of error for $D_{50}$ estimation versus sample size shown in the inset demonstrates that the error flattens out and becomes negligible after around 50 cores have been sampled. 
Fig. 4. (a) The effect of particle shape on the position of the $0.1 \%$ line in comparison to the recommendations of Church et al. (1987), (b) $0.1 \%$ line for individual samples from the River Rede Site A, in comparison to Church et al.’s line.

and discs were plotted (Fig. 4a). Particle shape is conventionally described according to the scheme devised by Zingg (1935) which uses measurements of the ratios between the long $(a)$, intermediate $(b)$, and short $(c)$ axis to define four basic shapes, viz. equant, rod-like, disc, bladed:

\begin{tabular}{lll}
\hline Equant & $b / a>0.67$ & $c / b>0.67$ \\
Rod & $b / a<0.67$ & $c / b>0.67$ \\
Disc & $b / a>0.67$ & $c / b<0.67$ \\
Blade & $b / a<0.67$ & $c / b<0.67$ \\
\hline
\end{tabular}

For each shape, theoretical maximum $a$ - and $c$-axes were calculated for a range of $b$-axes via back-calculation using the classification of Zingg (1935). For example, a disc with a $b$-axis size of $50 \mathrm{~mm}$ would have a maximum $a$-axis of $50 \mathrm{~mm}$ $(b / a=1)$ and a maximum $c$-axis of $33.5 \mathrm{~mm}$ $(c / b=0.67)$. A rod of the same size $b$-axis would have maximum $a$ - and $c$-axes of $74.6 \mathrm{~mm}$ and 50 $\mathrm{mm}$, respectively, and a blade would have $a$ - and $c$-axes of $74.6 \mathrm{~mm}$ and $33.5 \mathrm{~mm}$. Volumes were then calculated using the formulae given in Table 1. Assuming a standard sediment mineral density $\left(\rho_{\mathrm{s}}\right)$ of $2.65 \mathrm{~g} \mathrm{~cm}^{-3}$, grain weights throughout the sample were calculated and plotted against $b$-axis size (sieve diameter) to produce $0.1 \%$ lines for each shape. As expected, spheres plot along Church et al.'s line, whereas discs plot below. This suggests that for the same sample mass, a coarser truncation may be used for a sample dominated by disc-shaped particles compared with one dominated by spheres (thus representing a more relaxed criterion in comparison to Church et al.). Using the same procedure, 
the blade formula computes the same volume as a sphere of the same size $b$-axis which results in them plotting directly over the top of Church et al.'s line. Rod- and cube-shaped particles plot above Church et al.'s line, suggesting that both the latter should be truncated at a finer grain-size. The reason for this is that, assuming standard sediment mineral density throughout, cubes and rods each have a greater mass than a sphere of an equivalent-size $b$-axis.

In reality, sediments, including those sampled on the River Rede, will deviate from Church et al.'s $0.1 \%$ line as they are not composed exclusively of ellipsoids of revolution. This can be demonstrated when the $D_{99.9}$ (the percentile above which only $0.1 \%$ of the sample is larger) was extrapolated from each cumulative grain-size curve for samples taken from site A on the River Rede. Extrapolation is necessary, as it is extremely difficult to isolate $0.1 \%$ of the sample in the uppermost size class. These sizes were then plotted against the measured individual sample dry weight/0.001. A line plotted through the bivariate mean and using the same slope as Church et al., provides the $0.1 \%$ line for the Rede data (Fig. 4b). This is used in preference to linear regression which was found to provide a biased estimate of functional slope (see Mark and Church, 1977). The data tend to plot above and to the left of Church et al.'s line, suggesting that a larger sample size is required for a given grain-size or, alternatively, a finer truncation size should be applied for a given sample mass to adequately represent the river-bed sediment in the Rede. This would imply that Church et al.'s recommendations require refinement in order to account for the range of shapes encountered in natural upland gravel-bed rivers.

\subsection{Influence of particle shape upon plotting position}

The reason for these plotting positions is revealed when the particle shape of the River Rede sediments are further investigated using the classification of Zingg (1935) (Fig. 5). The shape distinctions defined by Sneed and Folk (1958) are also indicated for comparison. It is clear that the 'equant' grains (spheres and cubes) defined by Zingg (1935) plot in much the same position as the compact grains of Sneed and Folk (1958). Similarly Zingg's rods correspond to Sneed and Folk's elongate sediment, while the discs and blades of Zingg also broadly correspond to Sneed and Folk's plates and blades (although the $b / a$ axis ratio is rather blurred).

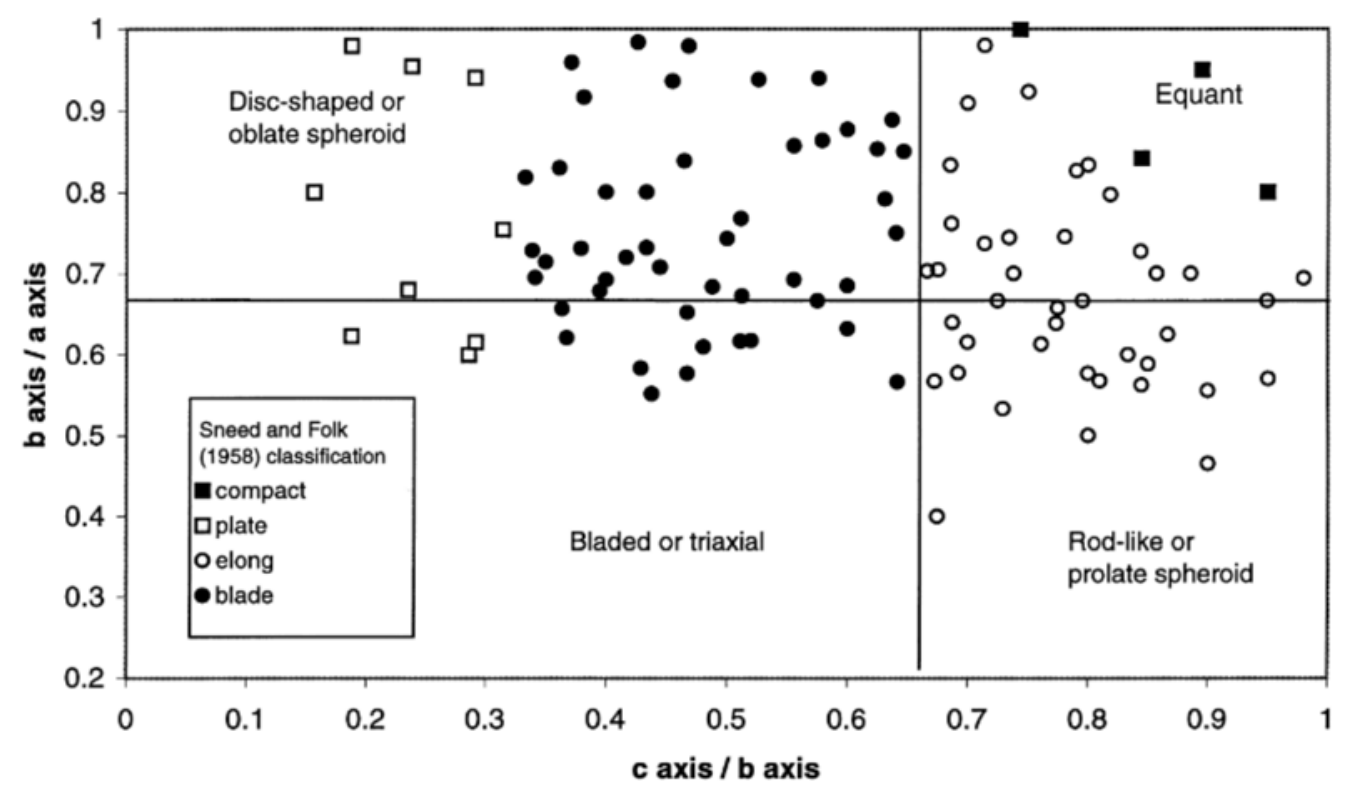

Fig. 5. Shape classification of the River Rede substrate sediments following the classification of Zingg (1935). That of Sneed and Folk (1958) is also included for comparative purposes and is indicated using symbols. 


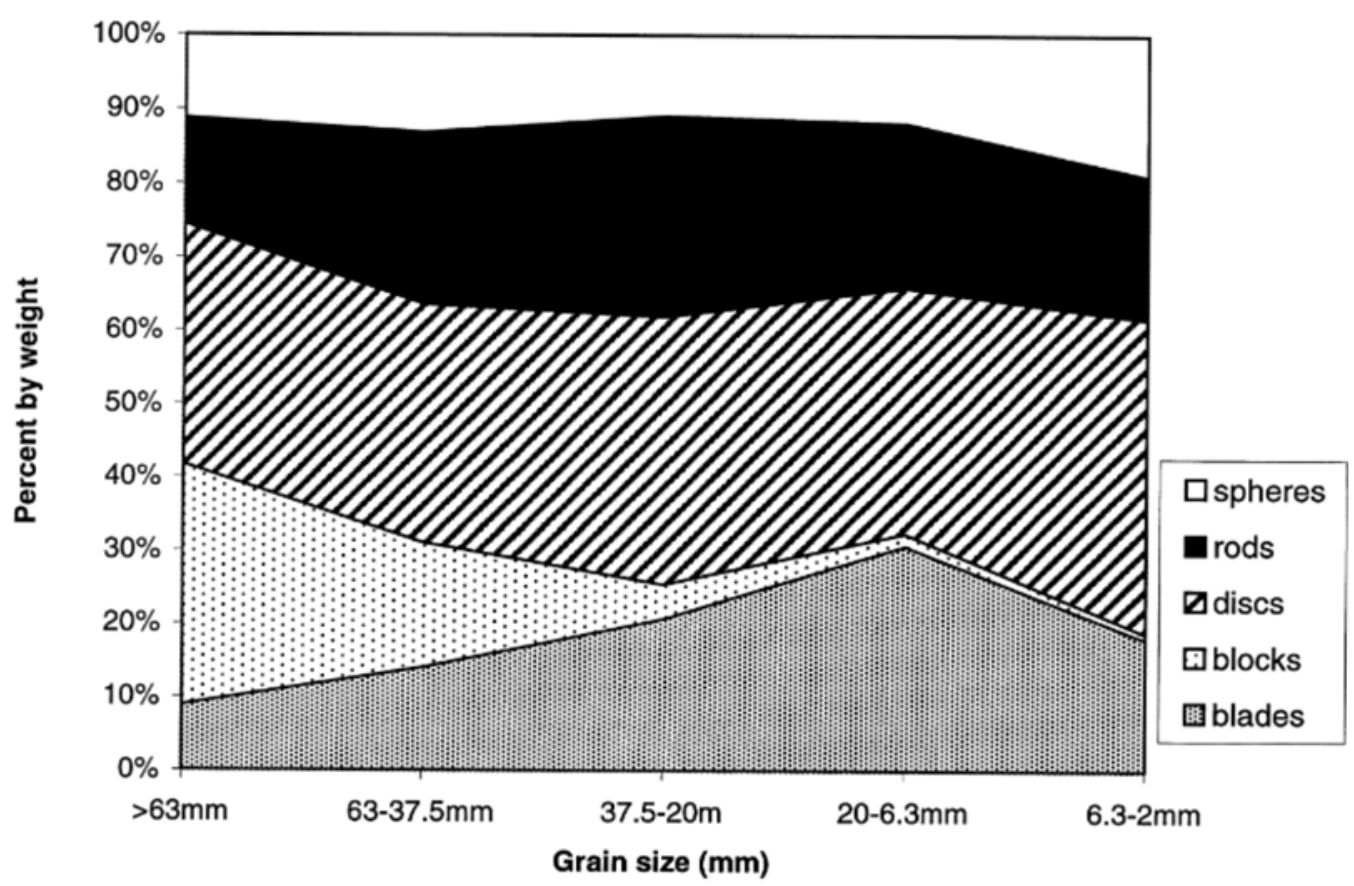

Fig. 6. Percentage distribution by weight of grain shape through different size categories for bulk sediment samples taken from the River Rede.

The Zingg (1935) equant category in the shape classification does not distinguish between spheres and cubes. Cubic (blocky) material was therefore described separately for the Rede bed material in order to differentiate from other shapes. The sample was dominated by discs at $40 \%$, while equants and rods both accounted for $22 \%$ and blades for $16 \%$. The relative proportions of spheres, rods and discs remain constant throughout. Cubes however tend to be much more frequent at the coarser tail of the distribution, where they accounted for $32 \%$ of the $>63 \mathrm{~mm}$ size fraction as compared to $0.8 \%$ of the 2-6.3 mm fraction (Fig. 6). In contrast, blades were much less frequent. It would appear that the increase in proportion of cubes in the coarser tail of the sample leads to the data plotting above the Church et al. $0.1 \%$ line for spheres and closer to the lines defined for rods and cubes (cf. Fig. 4).

\subsection{Particle sorting}

Particle sorting may also influence the position of the points relative to Church et al.'s line. Sorting was calculated using the Graphic Standard Deviation $\left(\sigma_{\mathrm{G}}\right)$ as defined by Folk (1974), which is computed as:

$\sigma_{\mathrm{G}}=\frac{\phi 84-\phi 16}{2}$

where $\phi 84$ and $\phi 16$ are the 84th and 16th percentiles of the grain size-distribution. Overall, the bed sediments of the River Rede were found to be very poorly sorted with a mean value for $\sigma_{\mathrm{G}}$ of 2.5. Sub-surface sediments tend to exhibit a bimodal grain-size distribution with a gravel framework and a finer matrix of sand, silt and clay. This well-developed fine-sediment population has a strong influence upon sorting: the greater the concentration of matrix population within a bimodal sample, the more poorly sorted will be that sample (Fig. 7). The significance of this factor is heightened when techniques designed to retain the finer-size fraction (such as the freeze-coring method used in this study) are employed. Such methods typically result in a more poorly sorted sample than would otherwise be obtained using conventional techniques such as grab sampling or pipe scoops. Fisheries ecologists who 


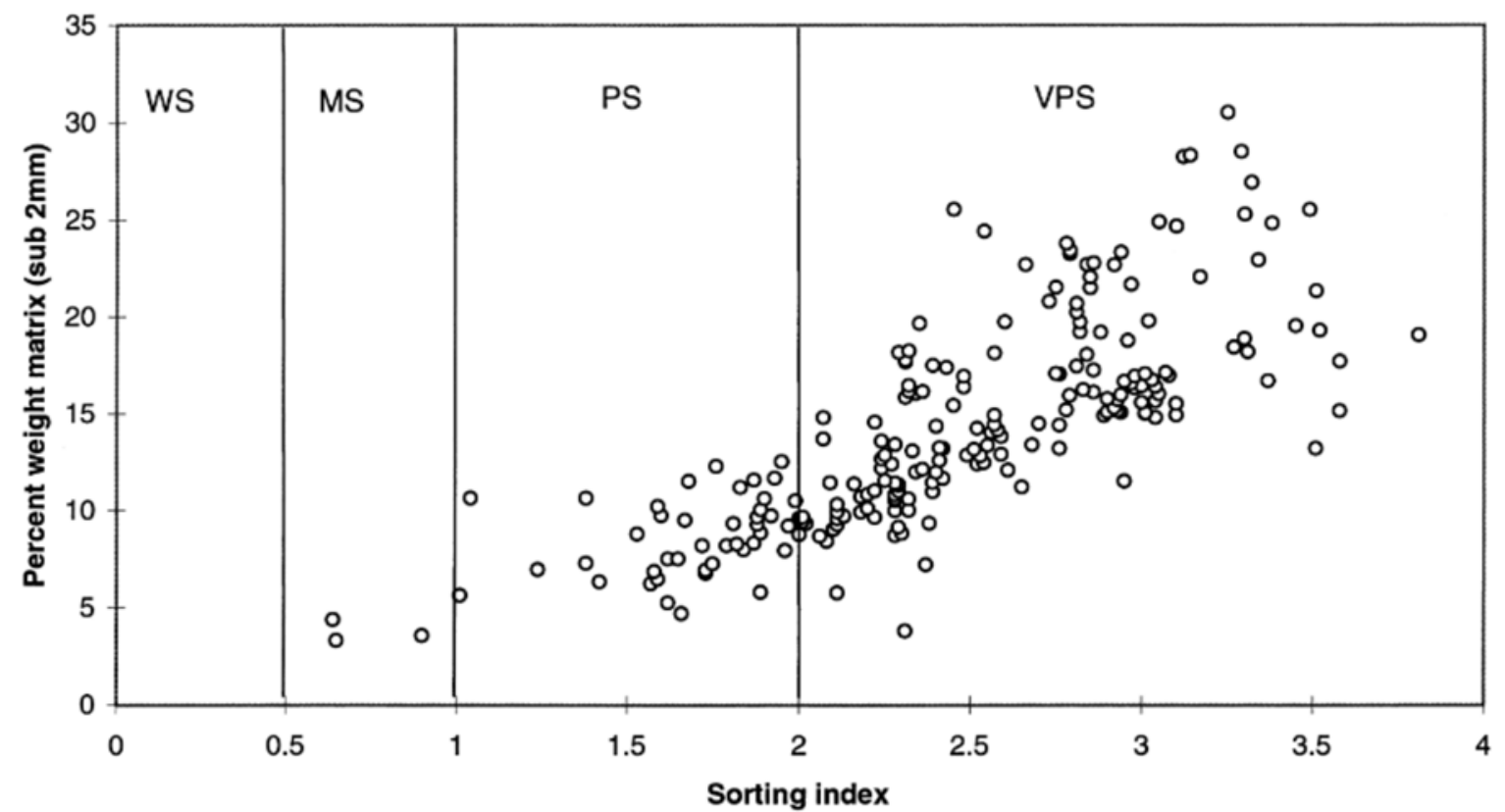

Fig. 7. The influence of matrix (sub $2 \mathrm{~mm}$ ) concentration upon sorting. The sorting index used is the Graphic Standard Deviation $\left(\sigma_{\mathrm{G}}\right)$ (Folk, 1974), which measures the deviation of the 16th and 84th percentiles $(\phi 84-\phi 16) / 2$, where $\phi n$ is the particle size in $\phi$ units at which $n \%$ by mass is finer. (WS = well sorted, $M S=$ moderately sorted, $P S=$ poorly sorted, VPS = very poorly sorted).

commonly use this technique should thus take this factor into consideration when estimating the sediment quality of fish spawning grounds.

The influence of sorting upon the truncation grain size was determined by plotting $0.1 \%$ lines for different sorting categories within the samples obtained from the River Rede. The line plotting through the bivariate mean provides a $0.1 \%$ line for the poorly sorted data (Fig. 8a) and the very poorly sorted data (Fig. 8b). These new charts are effectively a refinement of the Church et al. $0.1 \%$ sample standard, highlighting the need for either a coarser truncation or a larger sample compared to that required for well sorted ellipsoids of revolution. Whereas Church et al.'s $0.1 \%$ line recommends a sample weight of 362 $\mathrm{kg}$ to represent grains sizes up to $64 \mathrm{~mm}$, the lines derived from the Rede data recommend a weight of $782 \mathrm{~kg}$ for poorly sorted discs and $1035 \mathrm{~kg}$ for very poorly sorted discs (all figures rounded to the nearest integer). This equates to differences of $116 \%$ and $186 \%$, respectively.

\subsection{Testing the revised recommendations}

To check the robustness of these new sampling recommendations, a further 86 cores with a total dry weight of $1390 \mathrm{~kg}$ were retrieved from Site B (cf. Fig. 2). These were analysed to determine the minimum sample weight for the 99.9 percentile $(0.1 \%$ of the total mass excluded) and were plotted (Fig. 9). Sediments at Site B showed a similar shape distribution to those at Site A, and also contained blocky clasts at the $D_{99.9}$ grain-size. It is clear that the majority of points fall within the boundaries defined by discs and cubes indicating that the recommended sampling criteria may be applicable to other sites on upland gravel-bed rivers dominated by poorly sorted deposits with blocky clasts in the coarse tail of the distribution.

It is necessary to determine the effects of these more stringent sampling criteria on both the truncation grain size and on how statistically representative the sample remaining is after different degrees of truncation. 
Fig. 8. Recommended $0.1 \%$ lines for the River Rede Site B, based upon trends for (a) poorly sorted discs, and (b) very poorly sorted discs.

\subsection{Influence of truncation on grain size}

Table 3 demonstrates the recommended truncation size for samples obtained in this study using the cube line for very poorly sorted sediments from the River Rede (which may be considered as the most conservative sampling procedure to cover all shape and sorting factors). For comparison the recommendations of Church et al. and Mosely and Tindale (1985) are included. Single cores are only adequate to describe the grain-size distribution up to $12 \mathrm{~mm}$ ( $0.1 \%$ criterion), whereas Church et al. recommend truncating at $23 \mathrm{~mm}$ ( $0.1 \%$ criterion), and Mosely and Tindale (1985) at $85 \mathrm{~mm}$ (5\% criterion). Due to their smaller weight, individual core sub-samples may thus only describe the grain-size distribution up to 7 or $8 \mathrm{~mm}$ for very poorly sorted cubes, whereas Church et al. and Mosely and Tindale recommend truncation of 14 or $15 \mathrm{~mm}(0.1 \%)$ and $53 \mathrm{~mm}$ (5\%), respectively. Truncation influences the grain-size frequency distribution (cf. Fig. 3), due to a change in the normalising weight and grain-size range accepted into the analysis, which in turn influences percentile estimates. Truncation also affects the coarse tail of the distribution the most, demonstrated by a marked reduction in the mean $D_{84}$ value from $131 \mathrm{~mm}$ (no truncation) to $14.3 \mathrm{~mm}$ (truncated at the $0.1 \%$ level).

\subsection{Influence of truncation upon variance}

Church et al.'s truncation limits were interrogated statistically to determine if and how far they were representative for the River Rede. In doing this, it was assumed that the shape and sorting factors already described are reflected in the variability between cores in each size class. If the distribution of 
Fig. 9. Position of poorly sorted disc-dominated sediments from Site B in relation to (a) the recommended $0.1 \%$ line for poorly sorted disc line, and (b) the recommended $0.1 \%$ line for very poorly sorted discs.

$x_{i j}$, the percentage by weight of the $i$ th grain-size category in the $j$ th core is considered, the following model holds:

$x_{i j} \sim N\left(\mu_{i}, \sigma_{i}\right)$

where $\mu_{i}$ and $\sigma_{i}$ are parameters describing the way the percentage composition of the $i$ th grain-size category varies from core to core. While $\mu_{i}$ is the mean percentage composition of the $i$ th grain-size category, of particular interest here is the value of $\sigma_{i}$ (the standard deviation of the percentage composition of grain size $i$ ) for each grain-size category $(i)$.

Table 3

Recommended truncation sizes for total core and individual core sub-samples as a function of percentage of total sample mass based upon Milan et al. for very poorly sorted cubes, Church et al. (1987), and Mosely and Tindale (1985)

\begin{tabular}{lcclll}
\hline Core sub-sample and depth & $\begin{array}{l}\text { Mean dry weight } \\
(\mathrm{kg})\end{array}$ & $\begin{array}{l}\text { Size }(\mathrm{mm}) \text { 0.1\% } \\
\text { (this paper) }\end{array}$ & $\begin{array}{l}\text { Size }(\mathrm{mm}) \text { 0.1\% } \\
\text { (Church et al.) }\end{array}$ & $\begin{array}{l}\text { Size }(\mathrm{mm}) \text { 0.5\% } \\
\text { (Church et al.) }\end{array}$ & $\begin{array}{l}\text { Size }(\mathrm{mm}) 5 \% \\
\text { (Mosely and Tinsdale) }\end{array}$ \\
\hline A $(0-15 \mathrm{~cm})$ & 3.85 & 7 & 14 & 24 & 53 \\
B $(15-30 \mathrm{~cm})$ & 3.83 & 7 & 14 & 24 & 53 \\
C $(30-45 \mathrm{~cm})$ & 3.75 & 7 & 14 & 24 & 52 \\
D $(45-60 \mathrm{~cm})$ & 4.85 & 8 & 15 & 26 & 57 \\
Total $(0-60 \mathrm{~cm})$ & 16.32 & 12 & 23 & 39 & 85 \\
\hline
\end{tabular}


The lower this value is, the more representative is a measurement from a single core. Generally, if a measurement of $x_{i j}$ is taken from core $j$, then the overall percentage composition is likely to lie within the range (with a probability of 0.95 ). Thus, the smaller is $x_{i j} \pm 2 \sigma_{i}$, the more useful are individual core measurements.

For 166 cores, the weight contribution for each grain size was measured, and each of these was expressed as a percentage of the total core weight. Thus, for each grain-size category 166 percentages were computed, one for each core. In Fig. 10a, a
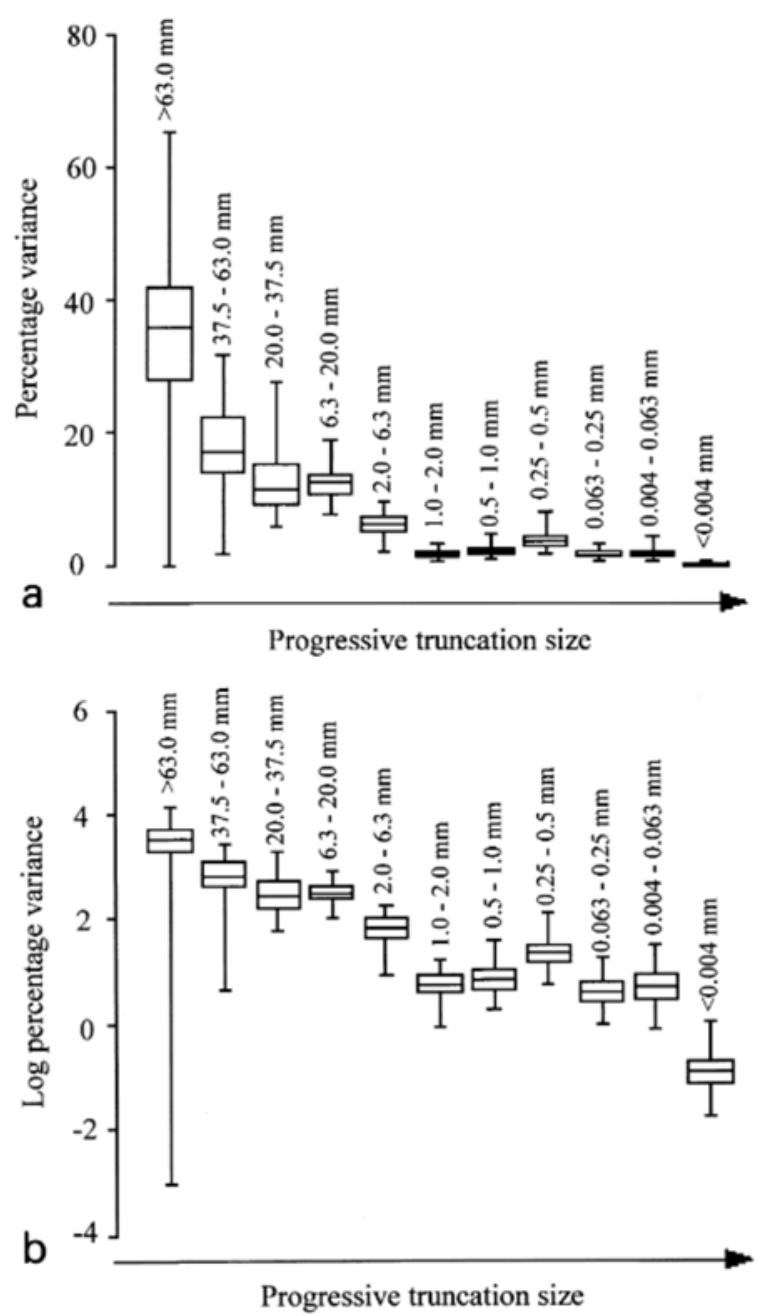

Fig. 10. The effect of truncation upon the variance within the total sample, after different levels of truncation: (a) percentage data, (b) log percentage data. series of parallel box-and-whisker plots show the variation in these percentages for each grain size, where it can be noted that variance reduces as progressive finer sieve fractions are removed and the data re-analysed. Generally the variance is reduced to a low constant value after the material in the sieves above $20 \mathrm{~mm}$ is removed. In order for the remaining sample to adequately represent the population of the bed of the river, a truncation limit slightly finer than that defined by Church et al., but parallel with those suggested for blocky samples in this study is suggested. In Fig. 10b the same data undergoing the transformation $z=\log (x+0.05)$ is shown. This transformation has the effect of stabilising the variances. Since these values are now statistically all the same, it is possible to refer to them by a single value, say $\sigma_{\log }$, and to estimate $\sigma_{\log }$, by a pooled estimate:

$\sigma_{\log }^{2}=\frac{\sum^{11}\left(z_{i j}-\overline{z_{i}}\right)^{2}}{n-11}$

Once this has been done, the individual grain-size fraction variances for each sieve fraction $\left(\sigma_{i}\right)$ can be found for the un-transformed variable as follows, expressing $x$ as a function of $z$ :

$g(z)=x=\exp (z)-0.05$

Here the standard deviation of $x, \sigma_{i}$ is approximately equal to $g^{\prime}\left(\mu_{z i}\right) \sigma_{\log }$ (see Bowman and Azzalini (1997, pp. 21-31 for a justification of this approximation). Thus, the individual sieve fraction variances $\left(\sigma_{i}\right)$ may be estimated from the data following progressive truncation of the coarsest size fractions (Table 4).

Notably, $\sigma_{i}$ is very large for the coarsest grain size, suggesting that this size fraction should be discarded. Re-analysing the new data set, truncated progressively at 63, 37.5, 20 and $6.3 \mathrm{~mm}$, and rescaled so that each total core mass is equal to 100 to allow comparison between cores of varying mass, demonstrates that the size of the variance decreases as truncation proceeds. Church et al.'s $0.1 \%$ criteria (cf. Table 3) suggest that $16.3 \mathrm{~kg}$ cores (mean core weight obtained from the River Rede sites A and B combined) should be truncated at $23 \mathrm{~mm}$ (which falls into the $20-37.5 \mathrm{~mm}$ size class. This figure corresponds to truncation level $>37.5 \mathrm{~mm}$ in Table 4 . However, even when this truncation is applied, $\sigma_{i}$ 
Table 4

Variance $\left(\sigma_{i}\right)$ estimates from percentage by weight grain size data of individual freeze-cores showing the effects of sample truncation

\begin{tabular}{|c|c|c|c|c|c|}
\hline & Whole sample & Truncate $>63 \mathrm{~mm}$ & Truncate $>37.5 \mathrm{~mm}$ & Truncate $>20 \mathrm{~mm}$ & Truncate $>6.3 \mathrm{~mm}$ \\
\hline$>63.00 \mathrm{~mm}$ & 15.3 & & & & \\
\hline $37.5-63.0 \mathrm{~mm}$ & 7.7 & 5.8 & & & \\
\hline $20.0-37.5 \mathrm{~mm}$ & 5.4 & 4.1 & 3.8 & & \\
\hline $6.3-20.0 \mathrm{~mm}$ & 5.4 & 4.0 & 3.7 & 3.6 & \\
\hline $2.0-6.3 \mathrm{~mm}$ & 2.8 & 2.1 & 1.9 & 1.9 & 1.9 \\
\hline $1.0-2.0 \mathrm{~mm}$ & 1.0 & 0.7 & 0.7 & 0.6 & 0.7 \\
\hline 500-1000 mm & 1.0 & 0.7 & 0.7 & 0.7 & 0.7 \\
\hline $250-500 \mathrm{~mm}$ & 1.8 & 1.3 & 1.2 & 1.2 & 1.2 \\
\hline $63-250 \mathrm{~mm}$ & 0.8 & 0.6 & 0.6 & 0.6 & 1.6 \\
\hline 4-63 mm & 0.9 & 0.7 & 0.6 & 0.6 & 0.7 \\
\hline$<4 \mathrm{~mm}$ & 0.2 & 0.1 & 0.1 & 0.1 & 0.1 \\
\hline
\end{tabular}

Variance decreases as progressively finer fractions are removed, with this being particularly evident after material coarser than 63 mm is discarded.

is still large, possibly due to the shape and sorting factors discussed earlier. The new criteria, accounting for grain shape and sorting, suggested in this paper indicate a finer truncation level (corresponding to truncation level $>20.0 \mathrm{~mm}$ in Table 4). It is clear that the size fraction variances show a reduction over those obtained using Church et al.'s $0.1 \%$ criteria, indicating that the remaining sample is more representative of the bed-material population.

\section{Discussion}

As a result of the influence of shape and sorting, the $D_{99.9}$ line for bed sediments obtained from the River Rede plots above Church et al.'s equivalent. Theoretical $0.1 \%$ lines presented for different shapes (Fig. 4a), indicate that blocky material such as cubes and rods require larger sample sizes in comparison to spheres due to their greater mass for an equivalent $b$-axis, whereas discs require smaller samples (assuming that the entire sample consists of similarly shaped material). Blades plot directly over spheres and therefore require equivalent sample sizes for them to be represented appropriately.

Sorting also appears to have an influence upon truncation limit, which modifies the shape recommendations slightly. A more poorly sorted deposit requires a larger sample in order to represent a given maximum grain size. Taking both shape and sorting factors into consideration, two new empirically derived $0.1 \%$ lines based upon poorly sorted and very poorly sorted sediments dominated by discs are presented (Fig. 8). From these diagrams, the line for very poorly sorted cubes effectively represents the most conservative sampling scenario for upland gravel-bed streams similar to the River Rede. It is recommended that this line is employed during field sampling where accurate estimates of coarser grain sizes are required.

\subsection{Influence of shape domination in the coarse tail}

The River Rede samples were dominated by discs throughout the grain-size distribution. However, weight differences between blocky material (which is more frequent in the coarse-size fraction in the Rede sediment) and discs, result in blocks having a greater influence on the weight of the $D_{99.9}$ particle used to define the representative sample weight. This is because the sampling criteria presented here are based upon the weight of a typical grain in the coarsest-size fraction compared with the total sample weight, and also assumes that the rest of the sample consists of grains of a similar shape. A blocky $D_{99.9}$ in a sample otherwise dominated by discs would lead to an unnecessary over-sampling of the bed material in order to represent the true population. This problem is impossible to correct without a complete knowledge of the sample shape distribution. One possible approach is to use the predominant particle shape throughout the sample when select- 


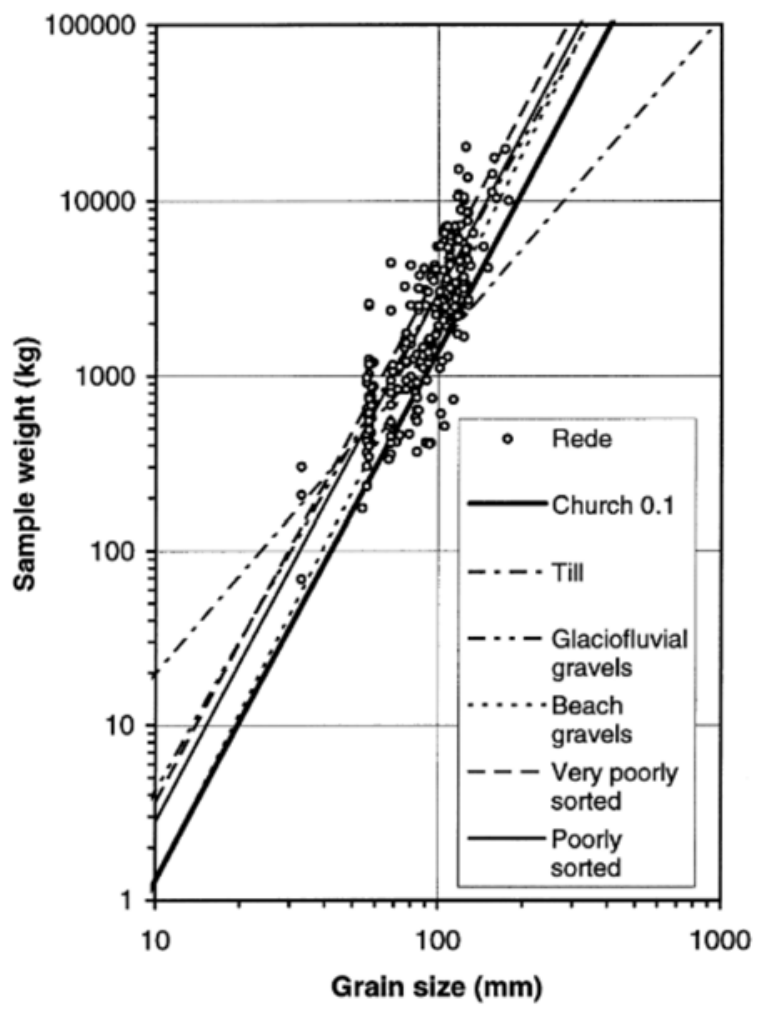

Fig. 11. The minimum sample size required to obtain reproducible results for poorly and very poorly sorted fluvial gravels. For comparison, the recommendations of Church et al. (1987) and Gale and Hoare (1992) are included.

ing sampling criteria to define the necessary sample weight, on the basis that the particular particle shape would then be appropriate to represent the bulk of the material retrieved.

\subsection{Comparison with recommendations for different sedimentary environments}

The results regarding the influence of sorting upon truncation size are supported by Gale and Hoare (1992). In Gale and Hoare's study, lines of equal sorting lay broadly parallel with the lines enclosing each depositional environment sampled. Poorly sorted ancient fluvial gravels and tills plotted above and to the left of Church et al.'s $0.1 \%$ line and had a much more gentle gradient; however, better sorted beach deposits plotted closer to Church et al.'s line and had a similar gradient (Fig. 11). Moderate to well sorted disc- and blade-shaped clasts, charac- teristic of beach deposits, are likely to plot below Church et al.'s line, and would require a smaller minimum sample size to sample a given maximum particle size in a representative fashion. Furthermore, beach deposits are less likely to contain blocky material in the coarser tail of the grain-size distribution. Very poorly sorted sediments obtained from the Rede plot almost directly on top of the glaciofluvial gravels, while poorly sorted sediments plot between Church et al.'s line and the glacio-fluvial line of Gale and Hoare (1992). There are two reasons for this. Firstly, the River Rede flows over, and has re-worked, glacio-fluvial deposits. Secondly, freeze-core techniques retrieve higher concentrations of fine-grained sediments resulting in more poorly sorted samples.

\subsection{A note on the application of truncation procedures}

The effects of truncation upon grain size distribution have been clearly demonstrated (Fig. 3). Descriptive indices such as sorting, skewness, kurtosis and geometric mean (used in the sedimentological literature) or the Fredle index (used in the fisheries literature) which require information on the tails of the distribution, are likely to be significantly altered as a result of truncation. Consequently, truncated data cannot be used to calculate these indices except for use in strictly standardised comparisons (Rood and Church, 1994). If truncated data are to be used in comparative studies (including ecological investigations), then it is important that a common truncation grain size is employed. In practice, however, many stream ecologists do not bother truncating the grain size distribution. This may, depending on the proportion of coarse clasts within the sample, have the effect of introducing a high degree of error concerning the concentration of fines. A further potential problem is that comparisons may be mistakenly made between truncated and untruncated data, leading to erroneous conclusions. Although truncation limits the information one can gain about the deposit, it is an essential procedure if temporal and spatial variability is to be assessed with any confidence. 


\section{Conclusions}

In essence, it can be concluded that it is essential to take particle shape and sorting into consideration before application of bulk sampling standards. This study has demonstrated the influence of particle shape and sorting upon the recommended sample mass for a given maximum particle size. Current recommendations which assume perfectly sorted ellipsoids of revolution (e.g. Church et al., 1987), may over- or under-estimate (a) the sample weight required, or alternatively (b) the appropriate truncation size. This is because they do not take into account variability in particle shape or degree of sorting. Rod- and cube-shaped particles are found to plot parallel to, but above, the $0.1 \%$ line of Church et al. indicating that more stringent sampling criteria are required in samples containing these shape types. Conversely, discs plot parallel and below Church et al.'s line, indicating that more relaxed criteria may be used, assuming that the sample is made up of broadly similar grain shapes. Blade-shapes plot directly over spheres.

The large concentrations of fine matrix sediments retained in freeze-core samples demonstrate the true poorly sorted nature of sub-surface channel-bed sediments which is often not revealed by other sampling methods. Milan (1994) has demonstrated that poorly sorted sediments with matrix concentrations of over $20 \%$ are not uncommon in British upland gravel-bed rivers and it is concluded that recommendations taking this factor into account are more realistic. Two new $0.1 \%$ reference lines based upon poorly and very poorly sorted discs are presented and indicate minimum sample weights/truncation sizes for different particle shapes. To avoid any bias which could be introduced by using linear regression, these lines follow Church et al.'s gradient and plot through the bivariate mean of the Rede data. These new standards are empirical, but were supported by data from a second site which plotted within the outer boundaries defined by discs and cubes, thus indicating that the proposed standards might be used at other similar upland gravel-bed river sites.

A statistical analysis of the River Rede freezecore data indicated that Church et al.'s truncation criterion still left some variation between samples. However, if the $0.1 \%$ line for cubes is applied, then size fraction variances are reduced. The final choice of sampling criteria rests with the investigator who has to decide upon the level of accuracy required for a particular study. Due to the empirical nature of this study, care should be taken when using any of the $0.1 \%$ reference lines given, as their position influences sampling recommendations for differently shaped material. Although the application of these new standards to other environments requires care, the most conservative scenario of very poorly sorted cubes in Fig. 8b provides a higher degree of accuracy and thus more confidence in data obtained using this sampling level. The assumption of a similar grain shape regardless of size remains; however, the general conclusions presented in this study regarding particle shape and sorting may be applied in principle to any sedimentological environment.

\section{Acknowledgements}

Special thanks are extended to Professor Michael Church for his very helpful review and the comments of another, anonymous referee are also appreciated. Professor Geoff Petts, University of Birmingham, kindly provided the freeze-sampling kit for the first phase of sampling, whilst Peter Donnelly and Richard Pawson are thanked for their assistance in the field. Anne Rooke kindly drafted Fig. 2.

\section{References}

American Society for Testing and Materials (ASTM), 1987. Standard Methods for Sampling Aggregates. ASTM D75-87.

Beyer, W.H., 1991. CRC Standard Mathematical Tables and Functions, 29 th ed. CRC Press, London.

Bowman, A.W., Azzalini, A., 1997. Applied Smoothing Techniques for Data Analysis. Oxford University Press, Oxford.

British Standards Institute (BSI), 1985. British Standards Testing Aggregates Part 103. Methods for Determination of Particle Size Distribution, BS 812, Part 103.

Church, M.A., McLean, D.G., Wolcott, J.F., 1987. River bed gravels: Sampling and analysis. In: Thorne, C.R., Bathurst, J.C., Hey, R.D. (Eds.), Sediment Transport in Gravel-bed Rivers. Wiley, Chichester, pp. 43-79.

de Vries, M., 1970. On the accuracy of bed material sampling. J. Hydraul. Res. 8, 523-533.

Ferguson, R.I., Paola, C., 1997. Bias and precision of percentiles of bulk grain size distributions. Earth Surface Process. Landforms 22, 1061-1077. 
Folk, R.L., 1974. Petrology of Sedimentary Rocks. Hemphill, London.

Gale, S.T., Hoare, P.G., 1992. Bulk sampling of coarse clastic sediments for particle size analysis. Earth Surface Process. Landforms 17, 729-733.

Gomez, B., 1983. Representative sampling of sandy gravels. Sediment. Geol. 34, 301-304.

Hey, R.D., Thorne, C.R., 1983. Accuracy of surface samples from gravel bed material. Proc. Am. Soc. Civ. Eng., J. Hydraul. Eng. 106, 842-851.

Klingeman, P.C., Emmett, W.W., 1982. Gravel bedload transport processes. In: Hey, R.D., Bathurst, J.C., Thorne, C.R. (Eds.), Gravel-bed Rivers. Wiley, Chichester, pp. 141-179.

Krumbein, W.C., Pettijohn, F.J., 1938. Manual of Sedimentary Petrography. Appleton-Century Inc., New York.

Mark, D.M., Church, M., 1977. On the misuse of regression in earth science. Math. Geol. 9, 63-75.

Milan, D.J., 1994. Sediment Quality Characteristics of Salmonid Spawning Grounds. Unpublished M.Phil. thesis, University of Technology, Loughborough.

Mosely, M.P., Tindale, R.S., 1985. Sediment variability and bed material sampling in gravel-bed rivers. Earth Surface Process. Landforms 10, 465-482.

Rice, S., Church, M., 1996. Sampling surficial fluvial gravels: the precision of size distribution percentile estimates. J. Sediment. Res. 66, 654-665.

Rood, K., Church, M., 1994. Modified freeze-core technique for sampling the permanently wetted stream bed. N. Am. J. Fish. Manage. 14, 852-861.

Sneed, E.D., Folk, R.L., 1958. Pebbles in the Lower Colorado River: a study in particle morphogenesis. J. Geol. 66, 114150.

Stocker, Z.S.J., Williams, D.D., 1972. A freeze-core method for describing the vertical distribution of sediments in a streambed. Limnol. Oceanogr. 17, 136-138.

Thoms, M.C., 1992. A comparison of grab- and freeze-sampling techniques in the collection of gravel-bed river sediments. Sediment. Geol. 78, 191-200.

Wentworth, C.K., 1926. Methods of Mechanical Analysis of Sediments. University of Iowa Studies in Natural History Vol. II, No. II.

Wolcott, J., Church, M., 1991. Strategies for sampling spatially heterogeneous phenomena: the example of river gravels. J. Sediment. Petrol. 61, 534-543.

Wolman, M.G., 1954. A method of sampling coarse river gravels. Trans. Am. Geophys. Union 35, 951-956.

Zingg, T., 1935. Beitrag zur Schotteranalyse. Schweiz. Mineral. Petrogr. Mitt. 15, 39-140. 